\title{
Primary School Teachers' Ability to Recognise Resilience in their Students
}

\author{
Rebecca Russo \\ James Cook University \\ Peter Boman \\ James Cook University
}

\begin{abstract}
This study investigated teachers' knowledge of, and capacity to identify resilience, in 92 primary school children in Far North Queensland. It was found that although teachers' knowledge of resilience was apparently strong, and they reported a significant level of confidence in their ability to assist children in building resilience, their capacity to identify levels of resilience in their students was lacking. The paper concludes with suggestions for future research.
\end{abstract}

\section{Introduction}

Resilience broadly refers to the tendency to spring back, rebound or recoil from adverse situations and involves the capacity to respond and endure, or develop and maintain a healthy life in spite of life stressors (Garmezy 1991). Werner (1990) suggested that resilient individuals adapt successfully and adjust rapidly to major life events. However, understanding resilience is a difficult task, for it is not a construct that once achieved will always be present. According to Zimmerman and Arunkumar (1994) resilience cannot be viewed as a fixed attribute that children either do or do not possess. Hence, children may be more or less resilient at different points in their lives, depending on the interaction between accumulation of individual and environmental factors over time (Howard, Dryden \& Johnson 1999, Rutter 1987).

In an attempt to reduce the affect of adverse circumstances and build resilience, researchers have identified an array of "protective factors" that involve both the 
attributes of children and their environments that are seen to promote successful development (Garmezy 1983, McClelland 2000, Minnard 2002, NMHWG \& NCCHC 2000, Rutter \& Rutter 1992). These protective factors are developed through children's interactions in diff e rent contexts that include family, friends, the community in which they live, and societal institutions such as schools (Rutter 1987, 2002). In general, p rotective factors allow children to become less vulnerable and hence more resilient ( G a rmezy 1985, Mandleco \& Craig 2000, Rutter 1987).

A common theme in the research on resilience has been to break down protective factors into internal and external assets (Howard \& Johnson 1999). Both internal and ext e mal assets are necessary in varying degrees for resilience to develop (Mandleco \& Craig 2000). The term "internal" involves children's personal attributes and qualities (Oswald, Johnson \& Howard 1999). Internal assets are intrinsic, inherent or generated f rom within an individual and include biological and psychological factors. These assets refer to children's health, genetic predisposition, temperament, gender, intellectual capacity, social competence, problem-solving skills, autonomy and a sense of purpose (Benard 1995). The review of the literature identifies many overlapping and intertwined resiliency traits within children that have been associated with successful adaptation under negative life stressors (Kaplan 1999).

The term "external" refers to children's family, peers, school and community relationships which can either protect against, or exacerbate, the negative impact of stress on his or her life (Kumpfer 1999). According to Kumpfer, resilience research categorises most high-risk individuals on the basis of living in a high-risk environment, rather than the absence of internal assets such as those discussed previously. Children's development is enmeshed in multiple contexts that alter over time (Kaplan 1999) and thereforeany attempt to analyse children and their developmental prog ress needs to fully consider the family and community to which they belong (Bowes \& Hayes 1999).

These assets have the potential to counteract possible negative outcomes in children's lives and promote the development of resilient qualities (Oswald et al. 1999). The more internal and external assets that children have, the more they are likely to display resilience. In contrast, if the number of risk factors in a child's life increases, their levels of resilience can decrease significantly (Mathews 2005). Risk factors refer to problems of biological maturity, unstable relationships with carers, inadequate parenting skills and poverty (Rutter 1993). Overall, the concepts of resilience and its internal and extemal assets are the positive counterparts to these risk factors (We rner \& Smith 1992).

According to a major mental health study in children and adolescents, a positive, rewarding school environment and a sense of connectedness to the school also 
promotes resilience (NMHWG \& NCCHC 2000). In addition, Garbarino and Abramowitz (1992) stated that the school-home interaction is one of the most important in children's lives and contributes to children being able to develop the needed sense of connectedness. Taylor and Macdonald (1998) identified that strong, positive and diverse links between school and home will benefit children, whereas a situation in which the two contexts work in opposition or in isolation will put childre n at risk. Benard (1993) suggested that schools can play a role in developing resilience in children because of the incredible stresses that the family system is now experiencing.

Studies by Rutter (1987), We rner and Smith (1988) have also recognised the significant contributions made by schools and their teachers in developing protective factors in their students. Schools are perhaps the most prominent social context in which children mature and are replete with opportunities to nurture children. Schools have a significant influence on the development of children because from the age of five, children spend a large part of their day in school, and these daily school experiences may affect them in multiple ways. Minnard (2002) emphasised that effective schools are those built on a foundation of protective factors, and can therefore provide students with security and greater opportunities to succeed. Rutter (1987) suggested that schools can endorse protective factors because they can promote improved selfesteem and self-efficacy by enabling children to develop important social and p roblem-solving skills.

Wang, Haertel and Walberg (1995) explained how schools can become a "home-awayf rom-home" for children, and teachers can became role models in whom the children can confide when their own families are threatened by dissolution. We rner and Smith's (1988) re se a rch discovered that next to families, teachers can be the most positive role models in the lives of resilient children. More over, Benard (1991, 1995) has argued that teachers play an important role in developing resilience in children through providing p rotective factors such as caring educational settings, positive and high expectations, and positive learning environments that are relevant and practical. Teachers can p romote educational resilience in children by reducing stress and providing positive support. However, in order for teachers to successfully recognise and assist children to be more resilient, it is necessary that their knowledge and awareness reflect the many complex factors that influence its development.

\section{Teachers' knowledge of resilience}

Oswald et al. (1999, 2003) studied the views of teachers in relation to resilience in children. The study investigated the beliefs of 477 teachers' from junior primary, primary and secondary schools in South Australia. Teachers completed a questionnaire on the important factors that influence the development of resilience. The findings of 
the study indicated that junior primary teachers believe the school to play the more important role in developing resilience. In contrast, primary and secondary teachers consider certain personality traits of children, and their family, to play the more significant role in developing resilience. Children are considered resilient by these teachers when they are "effective communicators, having a strong attachment with at least one adult, holding a personal belief in being able to achieve and be successful, and the acceptance of responsibility" (Oswald et al. 2003).

Similar results were also found in studies where interviews were conducted with primary school teachers on their views concerning what made resilient versus nonresilient children (Dryden, Johnson, Howard \& McGuire 1998, Howard \& Johnson 2000). According to Dryden et al., teachers refer frequently to the individual characteristics that children possess. Despite previously mentioned research on resilience, teachers in this study considered resilience to be mostly innate, that is, something that children do or do not have.

Howard and Johnson (2000) reported that teachers believed that having "a tough life" at home was the cause of students lacking resilience and being at-risk. In direct contrast to the students who believed that learning difficulties was a key to having "a tough life", teachers in this study did not believe that a lack of school achievement affected levels of resilience. That is, for teachers, being successful at school was not related to school life.

Not surprisingly, teachers tend to underestimate the potential or actual roles they might play in supporting children within their schools (Oswald et al. 1999, 2003). According to Oswald et al. (1999), when asked about the role schools play in promoting resilience, teachers considered the development of resilience to be highly related with student performance and academic success, rather than solid relationships with peers and staff and the quality of the school environment. In addition, Oswald et al. interviewed teachers about their views on the characteristics of resilience. The results of this study revealed two broad perspectives. While some teachers believed they could play an important role in the lives of children they educate and make valuable contributions, others believed they could have little impact during the time children are in their class and that both as adults and teachers they lacked the control or influence to alter situations.

Teachers' understanding of resilience may be affected by their pre-service training, the lack of professional development, or prior experience using the deficit model, which has dominated educational thinking (Mathews 2005, Zimmerman \& Arunkumar 1994). Most school-based prevention programs have employed a deficit model (Zimmerman \& Arunkumar), whereby certain 'inadequate' family backgrounds have been linked to 
lower educational benchmarks such as school completion rates, university entry, and performance on achievement measures (Hayes, Neilsen-Hewett \& Warton 1999). The deficit model targets at-risk groups rather than individuals assuming that the general societal factors are the principal determinants of success or failure (Hayes et al.). The impact of the deficit model may have affected teachers' ability to recognise characteristics of resilience in children and also underestimate their potential to influence its development.

Teachers need to be aware of the significant contributions they can make in developing resilience. According to Thielemann (n.d.), it is extremely important for teachers to understand the phenomenon of "resilience", in order to identify characteristics which help protect children against environmental stressors, and to understand how to create supportive academically enriched environments for their students.

While prior research suggests that teachers have some knowledge of resilience, research does not appear to have examined their ability to identify and recognise resiliency levels in children. However, one related study revealed that teachers, in comparison to the students' self-report, underestimated students' levels of optimism and their adjustment to high school (Boman 2002). It may not necessarily follow that having an understanding of resilience means that teachers are able to distinguish resilient or vulnerable children in their classrooms. Therefore, the aim of this study is to assess teachers' knowledge of resilience and to examine their ability to identify levels of resilience in their students.

\section{Method}

\section{Participants}

The participants in this study were 92 Year 4, 5, and 6 students and their nine teachers from three state schools in Far North Queensland, Australia. The schools were selected because between them they service a socially and economically diverse population. Only students with completed consent forms present on the day of collection were included in the study.

Data were obtained from a total of 43 male and 49 female students, aged between 8 and 12 with a mean age of 10.34 years. Eight female and one male teacher (T1-T9) from these nine classrooms were invited to participate in the study to rate their students' level of resilience. Although small in number, this sample of teachers had between 4.5 to 35 years of teaching experience with a mean of 20.61 years in the classroom. 


\section{Instruments}

Teacher questionnaire The nine participating teachers were asked to complete a questionnaire which was developed for this study to examine their relevant professional development experiences, knowledge of resilience, ability to identify resilience levels in children and their confidence in assisting children to build resilience. The questionnaire involved four components.

1. Professional development The teachers were asked how much professional development they had received in relation to resilience in children.

2. Resilience knowledge Ten traits related to resilience were rated using a four-point scale $(1$ = extremely unimportant, 2 = unimportant, 3 = important, and $4=$ extremely important). The traits originate from the International Resilience Project and have previously been used as a checklist for perceptions of resilience in children (Grotberg 1995).

3. Identifying Skills Teachers were asked to sort the children in their own class on a three-point continuum from vulnerable to resilient in order to indicate their level of resilience.

4. Capacity to assist Teachers were requested to express their level of confidence in assisting children to build resilience.

Teachers completed the four components in their own time, and all questionnaires were conducted within one week of the student's testing.

Resilience and Youth Development Module The primary school version of the Resilience and Youth Development Module (RYDM) (WestEd 2003) is a self-reporting resilience survey for year levels 4, 5 and 6. The RYDM is a component of the California Healthy Kids Survey developed by WestEd under contract to the California Department of Education. The survey has been used in the United States of America, Australia and South Africa (WestEd n.d.).

The RYDM assesses developmental protective factors critical to healthy development and academic success. In particular, the RYDM consists of two components totalling 59 questions. The first component is related to activities involving "risky behaviours". The second component is comprised of 21 questions on resilience and was used in this study. These questions measure the internal and external assets of the students. The resilience component of the RYDM, adopts a four-point response scale for 20 of the 21 questions. Students can indicate for each item how much it applies to them (1: "No, never", 2: "Yes, some of the time", 3: "Yes, most of the time", 4: "Yes, all of the time"). The remaining question has a two-point response scale (1: no or 4: yes). Mean scores are calculated to ascertain a level of resilience or vulnerability on both internal 
and external assets. The following scale (WestEd 2002) is used to report the student's level of resilience:

High students with an average item response above 3;

Moderate students with an average item response of at least 2 but below 3; and

Low students with an average item response of 2 .

\section{Results}

\section{Professional development}

Teachers formed two distinct groups in relation to professional development and resilience; those who had been involved in workshops which included elements of resilience and those who had never been involved in any related professional development (see Table 1). In total, three teachers (T4, T5, T8) reported on sessions they had attended which involved components on resilience. Participant T4 wrote that he/she had attended a resilience workshop. Participant T5 wrote that he/she had attended sessions involving "some components of some classroom behaviour management in-service presentations and elements of the Child Protection Policy that are relevant and/or address this issue. No specific professional development in relation to childhood depression and resilience". A similar response was also given from participant T8 who wrote that he/she was involved in a session "actually pertaining to stress, depression, etc with adults, but was usable with children - how to cope".

The remaining six teachers (T1, T2, T3, T6, T7 and T9) form the second group, whose response to the professional development question was "no". They indicated that they had not received any professional development in relation to resilience during their teaching careers.

\section{Resilience knowledge}

The teachers were asked to identify the importance of 10 statements in relation to resilience. The possible raw scores ranged from 10 to 40, with a perfect score of 40 indicating a strong understanding of resilience. By contrast a score of 10 indicated a very limited knowledge of resilience. Teachers' scores in this study ranged from 32 to 39. The mean was 35.11 with a standard deviation of 3.22 (see Table 1). 


\begin{tabular}{|c|c|c|}
\hline Teachers & $\begin{array}{c}\text { Professional } \\
\text { Development }\end{array}$ & $\begin{array}{c}\text { Knowledge of } \\
\text { Resilience }\end{array}$ \\
\hline T1 & No & 38 \\
\hline T2 & No & 39 \\
\hline T3 & No & 36 \\
\hline T4 & Yes & 32 \\
\hline T5 & Components & 32 \\
\hline T6 & No & 33 \\
\hline T7 & No & 40 \\
\hline T8 & Components & 32 \\
\hline T9 & No & 34 \\
\hline
\end{tabular}

\section{Table 1: Teachers' Level of Professional Development and Knowledge of Resilience}

A further analysis of the teachers' raw scores indicated that all the teachers rated the 10 statements as important or extremely important in helping children become more resilient. These results indicate that the teachers in this sample had a solid understanding of the factors that relate to resilience. Interestingly, the three teachers who had some professional development reported the lowest scores on knowledge of resilience.

\section{Identifying Skills}

To examine whether teachers could identify vulnerable or resilient students in their class, results between the teachers' ratings of the 92 students and the students' survey scores were compared. The results indicated that teachers in this sample had difficulty in identifying children in their class who self-reported high, moderate or low levels of resilience.

In terms of the internal assets, teachers did not accurately identify 54\% of the students who self-reported moderate and high levels of resilience (see Table 2). A similar result also was recorded for external assets as teachers did not correctly identify $52 \%$ of the students. To further emphasise that teachers were not successful at identifying their students' level of resilience, eight students who scored high on internal and external assets were rated by their teachers as being low. 


\begin{tabular}{|c|c|c|}
\hline Assets & $\begin{array}{c}\text { Percentage } \\
\text { matched }\end{array}$ & $\begin{array}{c}\text { Percentage } \\
\text { not matched }\end{array}$ \\
\hline Internal & 46 & 54 \\
\hline External & 48 & 52 \\
\hline
\end{tabular}

\section{Table 2: Teachers' Accuracy in Identifying Resilience and Vulnerability in Students}

\section{Capacity to assist}

The confidence statements made by each teacher regarding assisting students in building resilience are presented in Table 3. Six of the teachers felt confident in building resilience in their students. Of this group, two teachers made reference to courses that they had attended and professional readings related to resilience. The remaining teachers identified strategies as to how they could promote resilience in the classroom such as creating safe environments in the classroom, understanding a student's problem, adopting positive attitudes, classroom activities and home support. One teacher attributed their confidence in assisting students, to prior personal experience.

By contrast, two teachers reported that they did not feel confident in their ability to assist students in building resilience due to their lack of influence in the student's home environment. Finally, one teacher stated that they were not confident because of a lack of training in the area and not having the time to deal with these issues at school.

Results of this study support four key conclusions concerning this cohort of teachers:

a) they have received little or no professional development on resilience,

b) teachers appear to have a solid knowledge of resilience,

c) they have difficultly in identifying resilience levels in their students, and

d) most of the teachers were confident in their ability to build resilience in the classroom.

\section{Discussion}

This study found that, despite an obvious lack of professional development in the area of resilience, teachers' theoretical knowledge of resilience was sound. It also found that teachers had a perceived level of confidence in their ability to identify associated p rotective factors and to assist children in building resilience. However, teachers' 
ability to identify students who had or who lacked these protective factors was p roblematic. This finding suggests a gap between teachers' theoretical knowledge of resilience and the practical application of this knowledge in the classroom.

\begin{tabular}{|c|c|c|c|}
\hline & $\begin{array}{l}\text { Years of } \\
\text { teaching }\end{array}$ & Comment on confidence & $\begin{array}{l}\text { Professional } \\
\text { development }\end{array}$ \\
\hline T4 & 35 & $\begin{array}{l}\text { Yes, because of courses and readings and the support from } \\
\text { guidance officers and learning support staff. }\end{array}$ & Yes \\
\hline T5 & 18 & $\begin{array}{c}\text { Yes, Recent in-service in "Program achieve - You Can Do it" has } \\
\text { focus on fostering Rational Emotional Behaviour. Will implement } \\
\text { activities to development a positive mindset leading to social } \\
\text { emotional wellbeing and improve achievement. Also self-esteem } \\
\text { promoting activities based on multiple intelligences has worked } \\
\text { well to self-identify strong points and different perspectives to } \\
\text { being talented! }\end{array}$ & Components \\
\hline $\mathrm{T} 2$ & 31 & $\begin{array}{l}\text { Yes, by making myself available to the children and making the class } \\
\text { a safe environment. Understanding problems, not belittling children. }\end{array}$ & No \\
\hline T8 & 4.5 & Yes - successful activities. We talk about how to defeat bullying. & Components \\
\hline $\mathrm{T7}$ & 23 & Yes - possible teaching experience. & No \\
\hline $\mathrm{T} 1$ & 10 & $\begin{array}{l}\text { Yes, although it depends on whether I could work with their } \\
\text { children's family or guardians. There is much more success with } \\
\text { home support. Positiveness is essential attributes of a teacher to } \\
\text { begin to assist with depressed children. }\end{array}$ & No \\
\hline T9 & 25 & Not always -home factors intrude. & No \\
\hline T3 & 34 & $\begin{array}{c}\text { No, I can assist at school to a small degree but have little influence } \\
\text { on home causes. }\end{array}$ & No \\
\hline T6 & 5 & $\begin{array}{c}\text { Not really, I find that I don't have time at school to deal with it, and I } \\
\text { am not afraid of trying to help children because I'm not trained or } \\
\text { qualified in the area and don't know how to avoid mistakes, } \\
\text { thereby doing more damage! }\end{array}$ & No \\
\hline
\end{tabular}

Table 3: Teachers' Confidence in Building Resilience in Children

\section{Professional Development}

One of the fundamental findings in this study is that the majority of teachers have not been involved in any professional development about resilience. Two of the three teachers involved in professional development wrote that they had not attended programmes that directly covered these areas of resilience. Instead, components of resilience were embedded in programs related to bullying, behaviour management, stress or Child Protection Policy. This nesting of resilience issues in professional development programmes is of concern because teachers may not readily identify resilience or may attribute some components as being part of other broarder issues such as bullying. 
It may be fair to suggest that any professional development related to resilience would be better than none at all, however, some professional development could pose a number of problems. For example, the paucity of information given to teachers may trivialise or distort the complexity of resilience. This was evident from participant T8 who had previously attended a professional development session pertaining to stress and depression in adulthood, and now believed that the information obtained could be used with children in building resilience. This emphasises Briggs, Johnson \& Shepherd's (2002) notion that if teachers are required to provide supportive learning experiences for children to build resilience in the classroom then they need to be educated and well-informed of its complexities. This was not evident in the findings of the present study.

\section{Resilience Knowledge}

This study found that teachers have a sound knowledge of resilience traits, as the participants valued all the statements as being important or extremely important in building resilience. Most teachers were able to identify the factors which promote resilience. This result supports the findings of Oswald et al. (1999) who found that teachers were able to acknowledge the protective factors that are important for children to develop resilience.

This may suggest that it is relatively easy to identify resilience traits from the above questionnaire as the statements could be considered to be commonplace. That is, the statements reflect traits that could easily be linked to the concept of resilience without having any in-depth knowledge. Therefore, it is possible that teachers had a tendency to respond "important" or "extremely important" to the items which may have created a bias which is termed a response set (Hammond 2000). This could mean that the teachers' apparent knowledge of resilience is overestimated and somewhat superficial. This deficiency of knowledge could be attributed to the lack of professional development, teacher training and/or experience.

\section{Identifying Skills}

The second core role of teachers is to detect and respond to their students who need assistance. As a group, the teachers in this study were not successful in detecting students' self-reported status of resilience. This result is somewhat surprising given that these teachers believed they had a sound understanding of resilience. This tends to reinforce the initial conclusion that the depth of teachers' knowledge of resilience may be superficial. Teachers may understand concepts associated with resilience but they may not know how resilience or vulnerability presents itself in children.

However, this disparity may not be surprising. According to Argyris and Schon's (1974) espousal theory, a gap exists between what people think they know and their 
behaviour in applying this knowledge. That is, teachers may think they understand resilience but may not necessarily exhibit behaviours that reflect such knowledge. These results suggest that In order for teachers to be able to respond appropriately to children, it is imperative that they have a deeper and applicable knowledge of resilience so they are able to detect the students who require assistance and have skills to build on their strengths.

\section{Capacity to assist}

While teachers were unable to identify the resiliency level of their students, the majority of teachers felt confident in their ability to assist children to build their resilience. This supports the findings of Oswald et al. (1999) who disclosed two distinct views which involved teachers who felt confident in their ability to build resilience and teachers who felt that they had little impact on the lives of their students. In particular, teachers underestimate their role in providing protective factors for building resilience.

Oswald et al. (1999), and Howard and Johnson (2000), found that teachers underestimate their role in supporting children to develop protective factors in building resilience. However, it could be argued that if teachers had a deeper understanding, or knowledge of resilience, they would not underestimate their role in providing this support to students.

Overall, the findings indicate a contradiction between the teachers' reported theoretical knowledge of resilience and their ability to apply this knowledge in practice. Teachers in this study believe they can assist children to build resilience, however, their knowledge of resilience may be more superficial, and this lack of depth of understanding will ultimately impact upon the quality of assistance that their students are given.

\section{Limitations}

Certain limitations need to be considered when evaluating the results from this study. First, this study investigates the situation of children within the middle primary years (4-6) attending three schools in Far North Queensland and as such is limited in the broader applicability of its findings, to other schools, other regions or other age groups. A second limitation of the study is that it occurred on a single day for each school and so reflects the situation for the children and teachers on that single day, and as such is limited in its ability to reflect upon the ongoing development of knowledge of the teacher and resilience in the students. Third, the number of teachers used in the study is not sufficient from which to generalise.

\section{Avenues for further research}

Several future research areas are suggested by the current study. Students who were rated as vulnerable by their teachers, self-reported high levels of resilience. It would 
be beneficial to repeat the study with a larger number of teachers to confirm or disprove the hypothesis suggested by this small study that teachers experience difficulty in identifying resilience in their students.

Second, it would be useful to further explore teachers' understanding of resilience. While the International Resilience Project Checklist (Grotberg 1995) has been used in identifying perceptions of resilience, it might be more helpful to design a larger survey instrument that includes more internal and external assets. It may also be more helpful to interview teachers about their knowledge as this may provide more insight into the depth of this knowledge. Interview data may help explain the apparent disparity between teachers' knowledge and their ability to identify levels of resilience in their students.

Finally, it appears that teachers may have problems in identifying resilience levels in children even when professional development sessions have been attended. As most professional development sessions are limited in duration, it may be necessary to provide booster sessions on several occasions after the initial workshop. Therefore, further research could compare teachers who have had booster sessions with those who have not, and examine potential differences in their ability to identify resilience in children.

\section{Summary}

Due to their daily contact with children, teachers are considered to be the first line of assistance for children in building resilience (Miller, DuPaul \& Lutz 2002). Positive and caring teacher-student relationships are a source of support for children wanting to succeed especially when traditional structures for providing care deteriorate and children do not feel connected with their family (Oswald, et al. 1999). However, in order for teachers to build protective factors they require a solid understanding of resilience.

This present study linked teachers' theoretical knowledge of resilience to their ability to apply this knowledge in practice. This is an important step as previous studies have mainly concentrated on what teachers know, or believe, and not how this translates into classroom practice. The findings indicate that teachers in this study had a superficial knowledge of resilience yet most were confident in their ability to build resilience in their students. Overall, their ability to identify levels of resilience in their students was not as proficient as could be expected. As suggested, this gap between theoretical knowledge and practical application of this knowledge needs further investigation. 


\section{References}

Argyris, C. and Schon, D. (1974) Theory in practice: Increasing professional effectiveness, Jossey Bass, San Francisco.

B e mard, B. (1991) Fostering resilience in kids: Protective factors in the family, school and community, Westem Centre Drug-Free Schools and Communities, Portland, Oregon.

B e mard, B. (1993) Resiliency requires changing hearts and minds, Western Center News, vol. 62, pp. 27-29.

Be mard, B. (1995) Fostering Resilience in children, ERIC/EECE Digest, EDO-PS-99.

Boman, P. (2002) Optimism, pessimism, anger, and adjustment in adolescents, Unpublished doctoral thesis, University of South Australia.

Bowes, J. and Hayes, A. (eds) (1999) Children, families, and communities: contexts and consequences Oxford University Press, South Melbourn e.

Briggs, J. D., Johnson, W. E., Shepherd, D. L. and Sedbrook, S. R. (2002) Teacher attitudes and attributes concerning disabilities, Academic Exchange Quarterly, vol. 6, no. 2, pp. 85-90.

Dryden, J., Johnson, B. R., Howard, S. and McGuire, A. (1998) Resiliency: A comparison arising from conversations with 9-12 year old children and their teachers. Paper presented at the meeting of the American Educational Research Association. San Diego CA, April.

Garbarino, J. \& Abramowitz, R. (1992) Sociocultural risk and opportunity, in J.Garbarino, ed., Children and families in the social environment (2nd ed.), Aldine De Gruyter, New York, pp. 35-70.

Ga rmezy, N. (1983) Stressors of childhood, in N, Garmezy and M. Rutter, eds., Stress, coping and development in children, McGraw-Hill Book Company, New York, pp. 43-84.

Ga mezy, N. (1985) Stress-resistant children: The search for protective factors, in J. E. Stevenson, ed., Recent researd in developmental psychopathology: Journal of Child Psychology and Psychiatry Book Supplement, vol. 4, pp. 213-233.

Ga rmezy, N. (1991) Resiliency and vulnerability to adverse development outcomes associated with poverty, American Behavioral Scientist, vol. 34, no. 4, pp. 416-430.

Grotberg, E. (1995), "A guide to promoting resilience in children: Strengthening the human spirit", Retrieved: July 3, 2003.

$<$ http://resilnet.uiuc.edu/library/grotb95.html>

Hammond, S. (2000) Using psychometric tests, in G.M. Breakwell, S.Hammond, and C. Fife-Schaw, eds., Researd methods in psychology, Sage Publications, London, pp. 175-193.

Hayes, A., Neilson-Hewett, C. and Warton, P. (1999) From home to the world beyond: The interconnections among family, care and educational contexts, in J. Bowes and A. Hayes, eds., Children, families, and communities: Context and consequence, Oxford University Press, South Melbourne, pp. 94-144. 
Howard, S., Dryden, J. and Johnson, B. (1999) Childhood resilience: review and critique of the literature, OxfordReview of Education, vol. 25, no. 3, pp. 307-323.

Howard, S. \& Johnson, B. (1999) Tracking childhood resiliency, Children Australia, vol. 24, no. 3, pp. 14-23.

Howard, S. \& Johnson, B. (2000) What makes the difference? Children and teachers about resilient outcomes for students at risk, Educational Studies, vol. 26, no. 3, pp. 321-327.

Kaplan, H. (1999) Toward an understanding of resilience: A critical review of definitions and models, in M. Glantz and J. Johnson, eds., Resilience and development: Positive life adaptations, John Wiley and Sons, New York.

Kumpfer, K. (1999) Factors and processes contributing to resilience, in M. Glantz and J. Johnson eds., Resilience and development: Positive life adaptations, John Wiley and Sons, New York.

Mandleco, B. L. and Craig, P. J. (2000) Organisational framework for conceptualising resilience in children, Journal of Child and Adolescent Psychiatric Nursing, vol. 13, no. 3, pp. 99-112.

Mathews, R. (2005) The resilient child, InPsych, vol. 27, no. 2, pp. 20-22.

McClelland, A. (2000) No child: Child poverty in Australia, Brotherhood of St Laurence, Australia.

Miller, D., DuPaul, G. and Lutz, G. (2002) School-based psychosocial intervention for childhood depression: Acceptability of treatments among school psychologists, School Psychology Quarterly, vol. 17, no. 1, pp. 78-112.

Minnard, C. (2002) A strong building: A foundation of protective factors in schools, Children and Schools, vol. 24, no. 4, pp. 233-246.

National Mental Health Working Group (NMHWG) and National Community Child Health Council (NCCHC) (2000) Promoting the mental health and wellbeing of children and young people, in Discussion paper: Key principles and directions, NMHWG \& NCCHC, Canberra.

Oswald, M., Johnson, B. and Howard, S. (1999) "Quantifying and prioritising resilience factors: Teachers' Views”, Retrieved: September 28, 2003.

http://www.aare.edu.au/99pap/osw99728.htm

Oswald, M. Johnson, B. and Howard, S. (2003) Quantifying and evaluating resilience p romoting factors teachers' beliefs and perceived roles, Research in Education, iss. 70, pp. 50-64.

Rutter, M. (1987) Psychosocial resilience and protective mechanisms, American Journal of Orthopsychiatry, vol. 57, pp. 316-331.

Rutter, M. (1993) Cause and course of psychopathology: Some lessons from longitudinal data, Paediatric and Perinatal Epidemiology, vol. 7, pp. 105-120.

Rutter, M. (2002) Nature, nurture, and development: From evangelism through science toward policy and practice, Child Development, vol. 73, no. 1, pp. 1-21.

Rutter, M. and Rutter, M. (1992) Developing minds, Penguin Books, New York. 
Taylor, J. and Macdonald, F. (1998) Life at six: Life chances and beginning school, Brotherhood of St Laurence, Fitzroy.

Thielemann, J. (n.d.) "Identifying the resilient child: An emerging trend for America's inner-city schools", Retrieved: July 3, 2003.

http://employees.csbsju.edu/jmakepeace/Perspectives2k/f21Thielemann.jmm.doc

Wang, M. C., Haertal, G. D. and Walberg, H. J. (1995) Education resilience: An emergent construct, Temple University, Centre for Research in Human Development and Education, U.S. Department of Eduction.

Wemer, E. (1990) Protective factors and individual resilience, in S. Meisels and J. Shonikoff, eds., Handbook of Early Childhood Intervention, Cambridge University Press, New York.

Wemer, E. and Smith, R. (1988) Vulnerable but Invincible: A longitudinal study of resilient children and youth, Adams, Bannister and Cox, New York.

Wemer, E. E. and Smith, R. S. (1992) Overoming the odds: High risk children from birth to adulthood, Cornell University Press, Ithaca, New York.

WestEd (n.d.) "Healthy kids survey: Survey administration history", Retrieved: November 24, 2004.

http:www.wested.org/pub/docs/chks_survey_download.html

WestEd (2002) Resilience and youth development module: Aggregated California data (Fall 1999 - Spring 2002), Califoma Department of Education, Oakland, California.

WestEd (2003) Resilience and Youth Development Module: Elementary School Level, Califoma Department of Education, Oakland, Califomia.

Zimmerman, M. A. and Arunkumar, R. (1994) Resiliency Research: Implications for schools and policy, Social policy report: Society for research in child development, vol 4., pp. 13-35. 